\title{
EFEITO DA VELOCIDADE DE SECAGEM SOBRE A EMERGÊNCIA E VIGOR DE SEMENTES DE PUPUNHA (Bactris gasipaes Kunth) ${ }^{1}$
}

\author{
Sidney Alberto do N. FERREIRA ${ }^{2}$, Lenoir Alves dos SANTOS ${ }^{2}$
}

RESUMO - As sementes de pupunha perdem rapidamente a viabilidade quando sua umidade é reduzida, dificultando o seu transporte e armazenamento. Para determinar o efeito da velocidade de secagem, as sementes de pupunha foram submetidas às seguintes condições: a) meio ambiente de laboratório; b) dessecador com sílical gel na proporção de 1:1 (por peso); c) dessecador com sílica gel na proporção de 2:1. A cada dois dias, uma amostra de cada ambiente foi utilizada para testes de emergência e determinação da umidade. Conclui-se que: a) a viabilidade e o vigor das sementes de pupunha são dependentes da interação de sua umidade com a velocidade de secagem; b) a emergência e o vigor das sementes são afetados por pequenas reduções na sua umidade, além da velocidade com que esta é rebaixada; c) a secagem mais lenta favorece a emergência e o vigor das sementes de pupunha.

Palavras-chave: Pupunha, Semente, Recalcitrante, Secagem.

Effect of drying velocity over germination and vigour of peach palm (Bactris gasipaes Kunth) seeds

ABSTRACT - Peach palm (Bactris gasipaes Kunth, Palmae) seeds loose their viability rapidly if their humidity content is reduced, consequently reducing transport and seed storage success. To studying the effect of drying velocity, seeds were maintained in the following conditions: a) on the laboratory bench; b) in a desiccator jar with 1 part silica gel to 1 part seeds by weight; c) in a desiccator jar with 2:1 silica gel: seeds for 10 days, samples were taken every 2nd day for germination tests and humidity determinations. The results indicate that viability and vigour of the seeds are affected by both: the humidity content and the velocity of drying. Slower drying is more favorable for maintaining seed viability and vigour.

Key words: Peach Palm, Seeds, Recalcitrant, Drying.

\section{INTRODUÇÃO}

Como alternativa para o desenvolvimento agrícola da Amazônia, a pupunha (Bactris gasipaes Kunth) tem se destacado devido às suas múltiplas possibilidades de utilização, tais como fruto, farinha, palmito, ração, etc... (CLEMENT \& MORA URPI, 1987). Por ser uma planta nativa, a pupunha é adaptada às condições de solo e clima da região, além de ser de crescimento rápido quando comparada à outras palmeiras.

O crescente interesse por esta cultura, inclusive nas regiões nordeste e sudeste do Brasil, tem elevado anualmente a procura de semente. Contudo, apesar da popularidade da pupunha na Amazônia, é pequena a

1 Financiado pelo Conselho Nacional de Desenvolvimento Científico e Tecnológico - CNPq

2 Instituto Nacional de Pesquisas da Amazônia - INPA, CPCA, Caixa Postal 478, 69011-970Manaus-AM, Brasil 
disponibilidade de sementes selecionadas para um determinado fim. Além disto, as sementes de pupunha são de difícil armazenagem (FERREIRA, 1988), perdendo rapidamente sua viabilidade, o que dificulta seu fornecimento. A falta de técnicas adequadas tem causado perdas significantes quando do envio destas de uma localidade para outra (COATESBECKFORD \& CHUNG, 1987).

Para manter a viabilidade das sementes de pupunha é necessário protegê-las contra o excesso de secagem (FOURNIER, 1965; ALMEYDA \& MARTIN, 1980). O acondicionamento das sementes em meios levemente úmidos, tais como serragem de madeira, esfagno, limo turfoso, carvão vegetal e fibras de côco, foi sugerido (ibidem). FERREIRA \& SANTOS (1992) verificaram que a redução no teor de umidade de $45 \%$ para $30 \%$ foi suficiente para reduzir a emergência (germinação) e o vigor das sementes de pupunha. Assim, estas sementes enquadram-se dentro do grupo das chamadas sementes recalcitrantes (ROBERTS, 1973), ou intolerantes a grandes perdas de umidade.

Dentro deste grupo, há variações nos níveis de tolerância à secagem, embora a velocidade da perda da umidade seja algo bastante controvertido (KING \& ROBERT, 1980).

Em estudos com sementes de Avicennia marina (Forssk.) Vierh., sensíveis à dessecação, FARRANT et al. (1985) afirmaram que a secagem rápida, atingindo um menor conteúdo de umidade, é mais favorável para manter a viabilidade das sementes que uma secagem mais lenta. Assim, FARRANT et al. $(1986 ; 1988)$ propuseram um modelo para explicar o comportamento das sementes recalcitrantes de um modo geral, admitindo pequenas variações entre espécies, sem contudo alterar a importância de uma secagem mais rápida.

Neste trabalho avaliou-se os efeitos de diferentes períodos e velocidades de secagem sobre a viabilidade e vigor de sementes de pupunha.

\section{MATERIAL E MÉTODOS}

As sementes utilizadas foram extraídas de frutos no mesmo estádio visual de maturação, os quais possuiam características do grupo racial mesocarpa (MORA URPI \& CLEMENT, 1985), provenientes de um experimento, situado na fazenda da FUCADA, BR 174 - km 39, Manaus-AM. Essas foram postas de molho em água por quatro dias, com troca diária da água, a fim de facilitar a retirada do resto de polpa que fica aderido as mesmas. Em seguida, as sementes foram lavadas em água corrente, tratadas com um solução de hipoclorito de sódio a $1 \%$ por quinze minutos, e secadas à sombra por seis horas.

De modo a avaliar a condição inicial, uma amostra de 240 sementes foi utilizada para teste de emergência (germinação) e determinação do teor de umidade. $\mathrm{O}$ restante do material foi dividido em lotes iguais e submetidos as seguintes condições: 1) sobre bandeja em meio ambiente de laboratório; 2) em 
dessecador de vidro fechado contendo o mesmo peso de sementes e de sílica gel $(1: 1) ; 3)$ em dessecador contendo duas vezes mais o peso da sílica gel, em relação ao peso das sementes $(2: 1)$. Decorridos 2, 4, 6, 8 e 10 dias, amostras de 240 sementes de cada condição foram utilizadas para a determinação de umidade e teste de emergência. A cada retirada de semente, a sílica gel foi renovada, mantendo-se a relação inicial desta com as sementes.

A determinação do teor de umidade das sementes, tomando como base o peso úmido das mesmas, foi feto em estufa a $105^{\circ} \mathrm{C}$, durante 24 horas (BRASIL, 1976), utilizando quatro repetições de dez sementes por tratamento.

A semeadura foi feita em serragem velha, a uma profundidade de 1 $\mathrm{cm}$, utilizando-se quatro repetições de 50 sementes por tratamento. A avaliação da germinação foi feita através da contagem da emergência, a cada cinco dias, desde o aparecimento das primeiras plântulas até a estabilização. Como variável de vigor das sementes, foi calculado o índice de velocidade de emergência (IVE) (POPINIGIS, 1977).

$\mathrm{O}$ delineamento experimental foi inteiramente casualizado, em esquema fatorial ( 3 velocidade de secagem X 5 perídos de secagem), com quatro repetições. As médias dos tratamentos foram comparadas entre si pelo teste de Tukey ao nível de $5 \%$ de probabilidade.

\section{RESULTADOS E DISCUSSÃO}

Antes de serem submetidas à secagem as sementes de pupunha apresentavam um teor de umidade de $56 \%$ (Fig. 1), o que foi muito superior aos $45 \%$ encontrados por FERREIRA \& SANTOS (1922). Esta diferença, parece ser devido às variações de tamanho, formato e peso das sementes, típicos de diferentes populações de pupunha (MORA ZAMORA, 1986), e/ou a umidade do solo na época da colheita.

Sob condições de ambiente de laboratório, observou-se uma redução gradual no teor de umidade das sementes, que foi mais acentuada na presença de sílica gel na proporções de 1:1, e mais ainda com sílica gel na proporção de 2:1 (Fig. 1 e Tab. 1), embora os dois últimos não tenham diferido significativamente.

Como observado por FERREIRA \& SANTOS (1992), a redução no teor de umidade afetou significativamente a viabilidade e o vigor das sementes. Em ambiente de laboratório, a redução de $56 \%$ para $36 \%$ de umidade causou efeitos danosos sobre a emergência e o vigor das sementes de pupunha (Fig. 1).

A análise de variância preliminar detectou uma diferença entre a testemunha e os outros tratamentos e um efeito de interação significativo entre os períodos e as valocidades de secagens. Isto sugere que os fatores (períodos e velocidade de secagens) não agem independentemente, ou seja, para um determinado período de secagem a emergência e o vigor podem se comportar de formas distintas em relação às velocidades de secagens. Desta forma, as comparações das médias dos tratamentos foram feita estudando cada 


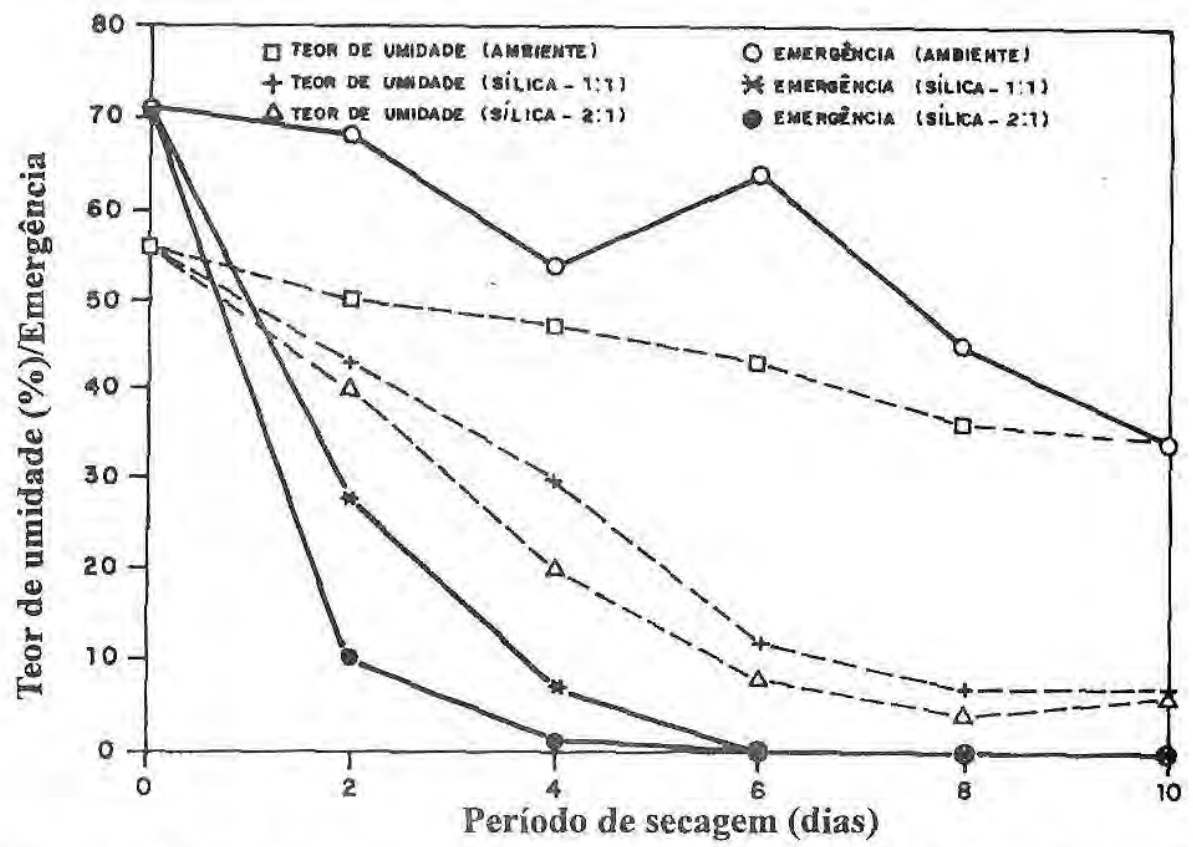

Figura 1. Dados reais da emergência e do teor de umidade referentes à sementes de pupunha com diferentes períodos e velocidades de secagem.

período de secagem em relação a cada velocidade e vice-versa (Tab. 1).

O que mais chama atenção é o fato da secagem sob ambiente de laboratório durante 6 e 8 dias ter porporcionado uma maior emergência $e$ índice de vigor (IVE) que as secagens em sílica gel (1:1 e 2:1) por dois dias, mesmos nestas tendo alcançado níveis de umidade equivalentes ou superior ao atingido sob condições de laboratório. Diante deste resultado, percebe-se que, para a manutenção da viabilidade de sementes de pupunha, é importante não só o grau de secagem, como também a velocidade com que este processo se dá. Assim, mesmo as sementes de pupunha apresentando comportamento recalcitrante (FERREIRA \& SANTOS, 1992), essas não se enquadram no modelo de FARRANTE et al.
(1986; 1988), em que afirmam que a secagem lenta aumenta a sensibilidade das sementes recalcitrantes e conseqüentemente proporciona uma menor emergência e vigor, quando comparada à secagem rápida.

\section{CONCLUSÃO}

Com base nestas observações conclui-se que: a) a viabilidade e vigor das sementes de pupunha são dependentes da interação do período de secagem com a velocidade de secagem; b) a emergência e vigor das sementes de pupunha são afetados por pequenas reduções no teor de umidade, além da velocidade com que este é rebaixado; c) uma secagem lenta das sementes de pupunha favorece a emergência e vigor, 
Tabela 1. Teor de umidade, emergência e indice de velocidade de emergêneia (IVE) das sementes de pupunha submetidas a diferentes periodos e velocidades de secagens ${ }^{(1)}$.

\begin{tabular}{|c|c|c|c|c|c|c|}
\hline $\begin{array}{l}\text { Ambiente } \\
\text { de secagem }\end{array}$ & \multicolumn{5}{|c|}{ Periodo de secagem (dias) } & Teste $F$ \\
\hline \multicolumn{7}{|c|}{ Teor de Umidade da Semente (\%) } \\
\hline Meio ambiente & $50,3 A$ & $47,2 A B$ & 42,98 & $36.2 \mathrm{C}$ & $34,2 \mathrm{C}$ & $26,3^{* *}$ \\
\hline Silica 1:1 & $43,3 \mathrm{~A}$ & $29,7 \mathrm{~B}$ & $\stackrel{a}{12.0 C}$ & $6,7 \mathrm{a}$ & $\begin{array}{c}\mathrm{a} \\
6,8 \mathrm{C}\end{array}$ & $47,4^{*-}$ \\
\hline & b & $\stackrel{b}{b}$ & $\stackrel{b}{?}$ & b & $=b$ & \\
\hline Sílica 2:1 & 39,9A & 19,98 & $7,8 \mathrm{C}$ & $\underset{b}{4,2 C}$ & $\underset{b}{5,7 C}$ & $25,7^{* *}$ \\
\hline Teste F & $15,7 * 0$ & $6,8^{\circ 00}$ & $6,0^{\circ * *}$ & $79,7 \cdots$ & $46,3^{\circ *}$ & - \\
\hline \multicolumn{6}{|c|}{ DMS (Periodo secagem) $=5,4$} & \\
\hline \multicolumn{7}{|c|}{ Emergência de Plântula (\%) ${ }^{(2)}$} \\
\hline Meio ambiente & $55,3 \mathrm{~A}$ & $47,1 B C$ & $53,3 A B$ & $42,7 \mathrm{CD}$ & 35,30 & $17,4^{* *}$ \\
\hline & a & & a & a & a & . \\
\hline Silica 1:1 & $31.7 \mathrm{~A}$ & $\underset{b}{15,38}$ & $\underset{b}{0,0 c}$ & $\begin{array}{c}0,0 \mathrm{C} \\
\mathrm{b}\end{array}$ & $\underset{b}{0,0 C}$ & $52,7^{0 *}$ \\
\hline Silica 2:1 & $17,6 \mathrm{~A}$ & $2,0 \mathrm{~B}$ & 0.08 & $0.0 \mathrm{~B}$ & 0.08 & $15,7^{* *}$ \\
\hline Teste F & $96,1^{\text {- }}$ & $41,8^{c}$ & $50,4^{b+*}$ & $60,8^{b *}$ & $10,3^{m+*}$ & - \\
\hline \multicolumn{6}{|c|}{ DMS (Ambiente secagem) $=6,6$} & \\
\hline \multicolumn{6}{|c|}{ Índice de Velocidade de Emergéncia (NE). } & \\
\hline Meio Ambiente & $0,627 A B$ & $0,558 \mathrm{AB}$ & $0,703 \mathrm{~A}$ & $0,501 B C$ & $0,329 \mathrm{C}$ & $10,8^{* *}$ \\
\hline Silica 1:1 & $0,236 \mathrm{~A}$ & $0,079 \mathrm{AB}$ & 0,0008 & 0,0008 & $0.000 \mathrm{~B}$ & $5,6^{* *}$ \\
\hline Silica 2:1 & $\begin{array}{c}b \\
0.078 A\end{array}$ & $0,005 \mathrm{~A}$ & $0,000 \mathrm{~b}$ & $0,000_{A}^{b}$ & $0,000 \mathrm{~A}$ & $0.6 \mathrm{NS}$ \\
\hline Teste F & $\begin{array}{c}c \\
42,8^{\circ}\end{array}$ & $48,2^{\text {se }}$ & $88,3^{\circ}$ & $44,8^{b}$ & $19,3^{b}$ & - \\
\hline \multicolumn{3}{|c|}{ DMS (Periodo secagem) $=0,173$} & \multicolumn{3}{|c|}{ DMS (Ambiente secagem) $=0,148$} & \\
\hline
\end{tabular}

1. As médias seguidas da mesma letra maiúscula na linha e mesma letra minúscula na coluna não diferem entre si ao nivel de $5 \%$ de probabilidade pelo teste de Tukey.

2 - Dados transformados em arco seno raiz quadrada da proporçăo.

* - Significativo ao nivel de $1 \%$ de probabilidade pelo teste $F$

NS - Nảo significativo ao nivel de $5 \%$ pelo teste $F$

em contraposição à secagem mais rápida, mesmo esta mantendo um maior teor de umidade.

\section{AGRADECIMENTOS}

Agradecemos ao Dr. Charles R. Clement e Dra. Isolde Dorothea K. Ferraz pela revisão do texto e sugestões apresentadas.

\section{Referências bibliográficas}

ALMEYDA, N.; MARTINS, F. W. 1980. The pejibaye. In: Cultivations of neglected tropical fruits with promise. USDA, pt.8, 10 p.

BRASIL - 1976. Ministério da Agricultura. Regras para análise de sementes. $188 \mathrm{p}$ CLEMENT, C. R.; MORA URPI, J. 1987. Pejibaye palm (Bactris gasipaes, Arecaceae): Multi-use potential for the lowland humid tropics. Economic Botany, 41 (2):302-311. 
COATES-BECKFORD, P. L.; CHUNG, P. C. 1987. A study of the germination, dissease symptoms and associated with pejibaye seeds. Seed Sci. \& Technol., 15:205-218.

FARRANT, J. M.; BERJAK, P.; Pammenter, N. W. 1985. The effect of drying rate on viability retention of recalcitrant propagules of Avicennia marina. $S$. Afr. J. Bot., 51(6):432-438.

FARRANT, J. M.; PAMMENTER, N. W.; BERJAK, P. 1986. The increasing desiccation sensitivity of recalcitrant Avicennia marina seeds with storage time. Physiol. Plant., 67:291-298.

FARRANT, J. M.; PAMMENTER, N. W.; BERJAK, P. 1988. Recalcitrant: a current assessment. Seed Sci. \& Technol., 16:155166.

FERREIRA, S. A. N. 1988. Armazenamento e desenvolvimento do teste de tetrazólio em'sementes de pupunha (Bactris gasipaes Kunth). Jaboticabal, UNESP/ FCAV. 64p. (Dissertaçăo de mestrado)

FERREIRA, S. A. N.; SANTOS, L. A. 1992. Viabilidade de sementes de pupunha (Bactris gasipaes Kunth). Acta Amazonica, 22(3):303-307.
FOURNIER, L. A. 1965. El pejibaye. O Bios, 1(7):11-15.

KING, M. W.; ROBERTS, E. H. 1980. A strategy for future research into the storage of recalcitrant seeds. In: CHIN, H.F. \& ROBERTS, E.H. (Coodr.). Recalcitrant crop seeds. Kuala Lumpur, Tropical Press. p. 90-110.

MORA URPI, J.; CLEMENT, C. R. 1985. Races and populations of peach palm found in the Amazon basin. In: C.R. CLEMENT \& L. CORADIN (eds.), Final report, Peach palm (Bactris gasipaes H.B.K.) germplas bank. US AID, project report. p. 107-141.

MORA ZAMORA, A. 1986. Descriptores de la semilla en tres poblaciones de pejibaye (Bactris gasipaes H.B.K.) e sus implicaciones filogeneticas. San Jose, Universidad de Costa Rica. 115p. (Trabalho de graduação).

POPINIGIS, F. 1977. Fisiologia da semente. Brasília, AGIPLAN. 289 p.

ROBERTS, E. H. 1973. Predicting the storage life of seeds. Seed Sci. \& Technol., 1:499514. 